\title{
Beneficial Effect of Early Treatment of Aberrant Mongolian Spots with 1,064-nm 0-switched Neodymium-Doped Yttrium-Aluminum -Garnet Laser
}

Jung Yup Kim

Won-Serk Kim

Department of Dermatology, Kangbuk Samsung Hospital, Sengkyunkwan University School of Medicine, Seoul, Korea
Received December 15, 2017

Revised December 19, 2017

Accepted December 19, 2017

\section{Correspondence}

Won-Serk Kim

Department of Dermatology, Kangbuk Samsung Hospital, Sungkyunkwan University School of Medicine, 29 Saemunan-ro, Jongno-gu, Seoul 03181, Korea

Tel.: +82-2-2001-2228

Fax: $+82-2-2001-2236$

E-mail: susinianaver.com

(C) Korean Society for Laser Medicine and Surgery

(c) This is an open access article distributed under the terms of the Creative Commons Attribution NonCommercial License (http://creativecommons.org/ licenses/by-nc/4.0) which permits unrestricted noncommercial use, distribution, and reproduction in any medium, provided the original work is properly cited.
Aberrant Mongolian spots are a benign cutaneous pigmentary disorder, which in contrast to sacral Mongolian spots, have tendency to persist without regression. Two young children with aberrant Mongolian spot were treated using Q-switched neodymium:yttrium-aluminum-garnet (Nd:YAG) laser under local anesthetic cream. In both cases, Q-switched $\mathrm{Nd}$ :YAG laser treatment was quite safe and effective. Early laser treatment may be a recommended treatment for aberrant Mongolian spots.

\section{Key words}

Aberrant Mongolian spot; Q-switched neodymium:yttrium-aluminumgarnet laser 


\section{INTRODUCTION}

In Asians, the incidence of Mongolian spots is very high and occasionally they may persist to adulthood. The extra sacral Mongolian spots are likely to persist, compared with the sacral Mongolian spots and are called as an aberrant Mongolian spot (AMS). Various Q-switched lasers have been tried for the treatment of AMS and excellent results were made. We report the beneficial effect for early laser treatment of AMS using Q-switched neodymium:yttrium-aluminum-garnet (Nd:YAG) laser.

\section{CASE REPORT}

\section{Case 1}

A 3-year old female patient presented with diffuse well demarcated bluish spot on the right thigh (Fig. 1A). The skin problem was congenital, not associated with any other medical or dermatologic problems. Skin biopsy was recommended, but was denied. Under the clinical diagnosis of AMS, she received five Q-switched Nd:YAG laser (Pastelle; Wontec; Pangyo; Korea) treatments with 3 month interval under local anesthesia using topical 2.5\% lidocaine cream. The treatment parameter was $1,064 \mathrm{~nm}$, 7-8 mm spot size, $1.5-2.0 \mathrm{~J} / \mathrm{cm}^{2}, 10 \mathrm{~Hz}$. After five repetitive treatments, she demonstrated marked clinical improvement without any adverse problem (Fig. 1B).

\section{Case 2}

A-2 year old female patient presented with congenital well-demarcated bluish patch on the right knee. As the patient grew, the color of skin lesion gradually darkened (Fig. 2A). She did not have any other medical problems or
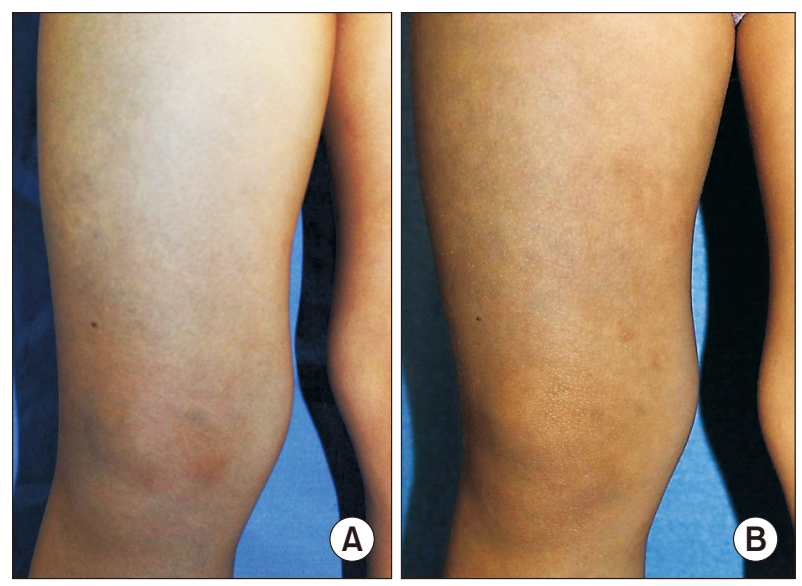

Fig. 1. Case 1 (A) Aberrant Mongolian spot (before treatment). (B) After several laser treatment. dermatologic problems. Under the clinical diagnosis of AMS, she had three 1,064 nm Q-switched Nd:YAG laser treatments (Pastelle) under local anesthesia using topical $2.5 \%$ lidocaine cream. The treatment parameter was 1,064 $\mathrm{nm}, 7-8 \mathrm{~mm}$ spot size, $1.5-2.0 \mathrm{~J} / \mathrm{cm}^{2}, 10 \mathrm{~Hz}$. After three repetitive treatments, she demonstrated marked clinical improvement without any adverse problem (Fig. 2B).

\section{DISCUSSION}

Mongolian spots are congenital hyperpigmented areas of varying size and shape, and usually confluent grayishblue in color. These are found most frequently in the sacral region, but so called AMS which involve extrasacral area is not rare. Sometimes, Mongolian spots involve large body area or are combined with other vascular malformation, and it is classified as extensive Mongolian spots. Mongolian spots are very common in children of Asian or African descent, but are relatively rare in Caucasians. 'The etiology of Mongolian spot is thought to result from a failure of migration of dermal melanocytes to the epidermis and their delayed disappearance from the dermal layer, so it is not neoplastic in nature but close to hamartoma. ${ }^{2}$

Some Mongolian spots persist without regression for long time and extensive AMS or AMS combined with portwine stain seems not to fade away. Epidemiology study of Mongolian spot in japanese school children showed that $7.64 \%$ of lesions are not regressed. ${ }^{3}$ Studies in adult population were $4.1 \%$ in 9996 young Japanese adults between 18 and $22,4,5$ and $2.88 \%$ in 800 middle age population.'

In general, AMS and even sacral mongolian spots over
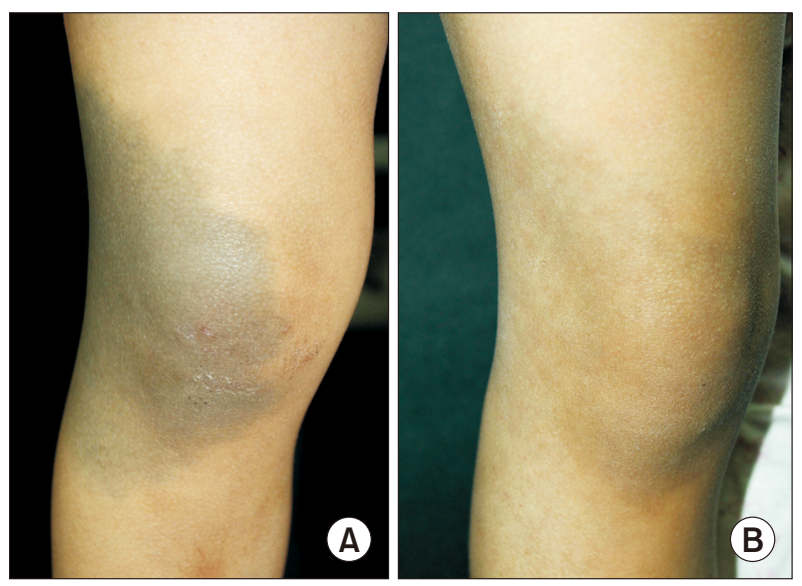

Fig. 2. Case 2 (A) Aberrant Mongolian spot (before treatment). (B) After several laser treatment. 
age 13 have less chance of spontaneous regression. So, active treatments using $Q$-switched lasers are recommended to reduce psychologic stress by pigment malformation. ${ }^{6-9}$

Some studies of Q-switched alexandrite laser for AMS showed acceptable results. Interestingly, children showed good response after two or three sessions, while adults needed more treatment sessions. The better result of children may be due to thinner and less pigmented skin in children which enabled effective transmission of the laser beam. ${ }^{6-8}$

Shirakawa's study about Q-switched ruby laser for AMS also showed that early treatment is more effective and leave less post-inflammatory hyperpigmentation compared to treatment in adulthood.

In our cases, we applied laser treatment for very young patients under 3 years old. They had excellent result without any side problems. In the laser treatment of children, increasing compliance by proper pain control is very important. Recent advanced laser technologies make less painful and faster treatment possible.

In summary, active laser treatment of AMS may be applicable to all ages and is highly recommendable for younger children because of the following reasons.

(1) AMS is likely to persist, compared with the sacral Mongolian spots.

(2) Considering the child's self-image is not fixed until sometime during the third year of life, active laser treatment under 3 year alleviated psychologic stress of patient and family members.
(3) Early treatment in child is more effective and safer and also saves time and cost due to small treated area.

\section{REFERENCES}

1. Kikuchi I, Inoue S. Natural history of the Mongolian spot. J Dermatol 1980;7:449-50.

2. Leung AK. Mongolian spots in Chinese children. Int J Dermatol 1988;27:106-8

3. Kikuchi I. Mongolian spots remaining in schoolchildren a statistical survey in Central Okinawa. J Dermatol 1980;7:213-6.

4. Hidano A. Persistent Mongolian spot in the adult. Arch Dermatol 1971;103:680-1.

5. Cole HN Jr, Hubler WR, Lund HZ. Persistent, aberrant mongolian spots. Arch Derm Syphilol 1950;61:244-60.

6. Kagami S, Asahina A, Uwajima Y, Miyamoto A, Yamada D, Shibata $\mathrm{S}$, et al. Treatment of persistent Mongolian spots with Qswitched alexandrite laser. Lasers Med Sci 2012;27:1229-32.

7. Kagami S, Asahina A, Watanabe R, Mimura Y, Shirai A, Hattori $\mathrm{N}$, et al. Treatment of 153 Japanese patients with $\mathrm{Q}$-switched alexandrite laser. Lasers Med Sci 2007;22:159-63.

8. Kagami S, Asahina A, Watanabe R, Mimura Y, Shirai A, Hattori N, et al. Laser treatment of 26 Japanese patients with Mongolian spots. Dermatol Surg 2008;34:1689-94.

9. Shirakawa M, Ozawa T, Ohasi N, Ishii M, Harada T. Comparison of regional efficacy and complications in the treatment of aberrant Mongolian spots with the Q-switched ruby laser. J Cosmet Laser Ther 2010;12:138-42. 